\title{
Dynamics of quality of life indicators in patients with gastroesophageal reflux disease comorbid with connective tissue dysplasia under the influence of complex treatment
}

\author{
Iryna B. Romash, Ivan R. Romash
}

Ivano-Frankivsk National Medical University, Ukraine.

\begin{abstract}
Introduction. In the case of gastroesophageal reflux disease (GERD) on the background of undifferentiated connective tissue dysplasia (UCTD) causes an even more significant deterioration in the QOL, including sleep disturbances and the onset of excessive daytime sleepiness (EDS). Thus, the study of the peculiarities of GERD on the background of connective tissue dysplasia and determining the impact of comorbid pathology on the $Q O L$ of patients with GERD is a topical issue in internal medicine. It has significant socio-economic significance. We believe that monitoring the most important variables that affect the quality of life of patients with GERD can help raise public awareness in this regard. In addition, it can guide the health care system to address these issues.
\end{abstract}

Purpose. The purpose of the work is to increase the awareness of medical workers about the scale of the problem and ways to solve it. to study the features of the dynamics of quality of life in patients with gastroesophageal reflux disease comorbid with connective tissue dysplasia under the influence of the proposed complex therapy.

Methodology. 120 patients were included: 65 men and 55 women. In 75 of them (Study Group) GERD was in the background of UCTD, in 45 (Comparison Group) - developed as an independent disease. The Study Group was divided into three groups. comparison Group - 45 patients with GERD without UCTD, received basic standard therapy, which included PPI "Panocid" 40 mg once a day and alginate-antacid formulation (Gaviscon Double Action Liquid) 20 ml, 3 times per day after meals and before bedtime. I Group - 25 patients with GERD +UCTD, which to the standard basic therapy was added "Magne-B6" for 2 tablets 3 times per day. II Group - 25 patients with GERD + UCTD, which to the standard basic therapy was added "Calcium-D3 Nicomed" 1 tablet 3 times per day. III Group - 25 patients with GERD + UCTD, who used the drug "Magne-B6" 2 tablets 3 times per day and "Calcium-D3 Nicomed" 1 tablet 3 times per day on the background of standard basic therapy. The Medical Outcomes Study 36-Item Short-Form Health Status (SF-36), the Gastrointestinal Symptom Rating Scale (GSRS), and the scale of "Personal and social performance" (PSP) - were used to study patients in detail. A comprehensive examination of patients was performed twice: before and after 30 days of comprehensive treatment.

Results and Discussion. Under the influence of the basic therapy in Comparison Group the General Health $(\mathrm{GH})$ improved by $33.03 \%$. While in the groups on the background of complex treatment is increased by $42.52 \%$ in patients of the I Group, by $13.10 \%$ in patients of the II Group, and $46.28 \%$ in patients of the III Group (p1, p2, p3 <0.05). Physical Functiong Scale (PF) improved by $17.9 \%$ in patients of the Comparison Group ( $p<0.05$ ) and by $30.38 \% ; 27.47 \%, 29.17 \%$, respectively (p1, p2, p3 <0.05). Role Physical Scale (RP) scores improved by $25.14 \%$ in Comparison Group (p <0.05) and by $33.6 \%, 22.58 \%$ and $40.20 \%$ respectively (p1, p2, p3 $<0.05$ ). Dynamics of data in Body Pain (BP) scale improved by $21.84 \%$ in patients of the Comparison Group (p <0.05) and by 37.28\%, 25.46\%, 35.92\% (p1, p2, p3<0.05).As can be seen from it, under the influence of complex therapy, the values of the Vitality (VT) increased by $17.18 \%$ in patients of Group I, by $21.93 \%$ - in Group II, by $37.87 \%$ - in Group III (p1, p2, p3 <0.05). Among 
patients of the Comparison Group, the influx of strength and energy felt $9.50 \%$ ( $p<0.05)$. Data of Social Functioning Scale (SF) improved by $8.8 \%$ in patients of the Comparison Group ( $\mathrm{p}<0,05)$ and by 22.7\%, 29.6\%, 29.31\%, respectively[p1, p2, p3 <0.05). Mental Health Scale (MH) improved by $17.23 \%$ in patients of Group I, by $22.41 \%$ - in Group II, by $21.96 \%$ - in Group III (p1, p2, p3 <0.05) and 14.22\% - in the Comparison Group ( $p<0.05$ ). Also in patients were positive dynamics of the Role Emotional functioning scale (RE): by $27.37 \%$ in patients of Group I, by $12.36 \%$ - in Group II, by 15.7\% - in the Group III (p1, p2, p3 <0.05) and 9.05\% - in patients of the Comparison Group ( $\mathrm{p}<0.05)$.

Conclusions. Thus, the inclusion in the standard therapy of gastroesophageal reflux disease in patients with its development on the background of undifferentiated connective tissue dysplasia of magnesium lactate dihydrate in combination with pyridoxine hydrochloride ("Magne -B6 ") and calcium carbonate in combination with cholecalciferol ("Calcium-D3 Nicomed") contributed to a significant improvement in their quality of life.

\section{Keywords}

quality of life, gastroesophageal reflux disease, comorbidity, connective tissue dysplasia, complex treatment.

\begin{abstract}
Address for correspondence:
Romash Iryna Bohdanivna, MD, Ph.D., assistant of professor Department propaedeutics of internal medicine, Ivano-Frankivsk National Medical University. 76010 Ivano-Frankivsk, Ukraine.e-mail: iromash@ukr.net; iromash@ifnmu.edu.ua
\end{abstract}

This work is licensed under a Creative Commons AttributionNonCommercial 4.0 International License (CC BY-NC 4.0). (c) (i) (8)

(C) Copyright: the Author(s), 2020

Licensee NDSAN (MFC- Coordinator of the NDSAN), Italy doi: https://doi.org/10.32437/mhgcj.v4i2.127
Submitted for publication: 23 April 2021

Revised: 17 August 2021 Accepted for publication: 24 October 2021

\section{Introduction}

The problem of comorbid pathology in the patient XXI century becomes the rule rather than the exception. It causes significant costs for the diagnosis and treatment of such patients, and ultimately high disability and mortality.

Epidemiological studies in recent years have shown that gastroesophageal reflux disease (GERD) occupies a leading position among other acid-dependent gastrointestinal diseases and is a significant factor in health care costs. Depending on the study population, its prevalence is in the range of $10-30 \%$ and tends to increase (Charles Hill et al. 2020). Over the past 40 years, the incidence of GERD has increased significantly and has become one of the main clinical problems in gastroenterology. In North America, it is noted in 18.1-27.8\%, in Europe - in 2.5-7.8\%, in the Middle East - in $8.7-33.2 \%$ of cases. GERD is also increasingly found in Asians, where its prevalence averages about $8 \%$.

According to research by Gorczyca $R$ et al. (2019) and ludici M et.al. (2017) already in patients with GERD without concomitant pathology, the quality of life deteriorates due to functional limitations, emotional disorders, increased frequency of reflux. Patients with GERD usually suffer from a variety of symptoms, including acid regurgitation, epigastralgia, non-cardiac chest pain, chronic cough, asthma. Symptoms of nocturnal acid regurgitation may interfere with sleep. Therefore, patients with GERD may experience a loss of quality of life (QOL) much more often than the general population. (Salome Satya Vani $P$ et al., 2018). And this in turn affects the ability of people to perform daily activities, which closely affects the state of their well-being.

The urgency of the problem of GERD in addition to a serious impact on $\mathrm{QOL}$ and social functioning is the development of dangerous to the health 
and life of patients complications: esophageal stricture, peptic ulcer, Barrett's esophagus, adenocarcinoma. Therefore, early diagnosis of the underlying disease and comorbid conditions is important to prevent the above complications. By the way, digestive disorders are increasingly recognized as one of the leading causes of disability worldwide. In 2019, these diseases took third place after cardiovascular and cancer diseases

In the case of GERD on the background of undifferentiated connective tissue dysplasia (UCTD) causes an even more significant deterioration in the $\mathrm{QL}$, including sleep disturbances and the onset of excessive daytime sleepiness (EDS). This dependence is indicated by our previous correlation analysis and the establishment of a direct close relationship between the indicator of pathological acidification of the esophagus (acid exposure time - AET) and EDS in both groups. In our previous study, we found a significant decrease in $Q \mathrm{OL}$ and social functioning (Romash, 2019, 2020). In particular, patients with a combination of GERD and UCTD significantly more often worried about heartburn, impaired quality of sleep, and life on 1.4 times $(p<0.05)$. They increased the frequency of gastroesophageal reflux with $\mathrm{pH}<4$, increased the number of acid reflux in the supine and standing positions.

Thus, the study of the peculiarities of GERD on the background of connective tissue dysplasia and determining the impact of comorbid pathology on the $Q O L$ of patients with GERD is a topical issue in internal medicine. It has significant socio-economic significance

We believe that monitoring the most important variables that affect the quality of life of patients with GERD can help raise public awareness in this regard. In addition, it can guide the health care system to address these issues

\section{Purpose}

The purpose of the work is to increase the awareness of medical workers about the scale of the problem and ways to solve it. to study the features of the dynamics of quality of life in patients with gastroesophageal reflux disease comorbid with connective tissue dysplasia under the influence of the proposed complex therapy.

\section{Design/Methodology/Approach}

120 patients have included 65 men and 55 women. In 75 of them (Stady Group) GERD was in the background of UCTD, in 45 (Comparison Group) - developed as an independent disease. Depending on the treatment regimen, the experimental group was divided into three.

Comparison Group consisted of 45 patients with GERD without connective tissue disorders, who received basic standard therapy, which included PPI "Panocid" and alginate-antacid formulation (Gaviscon Double Action Liquid) $20 \mathrm{ml} 3$ times per day after meals and before bedtime.

I Group consisted of 25 patients with GERD in combination with UCTD, which was added to the basic therapy "Magne-B6" for 2 tablets 3 times per day.

I Group consisted of 25 patients with GERD on the background of UCTD, which was added to the basic therapy "Calcium-D3 Nicomed" 1 tablet 3 times per day.

III Group consisted of 25 patients with GERD in combination with UCTD, which was added to the basic therapy "Magne-B6" in 2 tablets. 3 times per day and "Calcium-D3 Nicomed" 1 tablet 3 times per day.

The Medical Outcomes Study 36-Item ShortForm Health Status (SF-36), the Gastrointestinal Symptom Rating Scale (GSRS), and the scale of "Personal and social performance" (PSP) - were used to study patients in detail.

A comprehensive examination of patients was performed twice: before and after 30 days of comprehensive treatment

The sample of patients was representative by age and gender ( Table 1).

Table 1.

Distribution patients by age and sex

\begin{tabular}{|l|l|l|l|l|}
\hline Indexes & $\begin{array}{l}\text { Comparison } \\
\text { Group } \\
(\mathrm{n}=45)\end{array}$ & $\begin{array}{l}\text { I } \\
(\mathrm{n}=25)\end{array}$ & $\begin{array}{l}\text { III } \\
(\mathrm{n}=25)\end{array}$ & $\begin{array}{l}\text { III } \\
(\mathrm{n}=25)\end{array}$ \\
\hline Age & $46.2 \pm 3.03$ & $36.2 \pm 3.03$ & $32.2 \pm 3.03$ & $29.2 \pm 3.03$ \\
\hline \multicolumn{7}{|l|}{}
\end{tabular}




\begin{tabular}{|l|l|l|l|l|l|l|l|l|l|}
\hline $\begin{array}{l}\text { Gender } \\
\text { (abs. number,\%) }\end{array}$ & Male & 23 & 51.2 & 14 & 56.0 & 15 & 60.0 & 13 & 52.0 \\
\cline { 2 - 10 } & Female & 22 & 48.8 & 11 & 44.0 & 9 & 40.0 & 12 & 48.0 \\
\hline
\end{tabular}

After reviewing the examination procedure and the principle of treatment, all patients voluntarily signed written agreements following the protocol of the clinical trial approved by the Bioethics Commission of Ivano-Frankivsk National Medical University. To assess the dynamics of quality of life (QOL) of the examined patients under the influence of complex treatment, each patient was asked to fill out a short form of the questionnaire Medical Outcomes Study 36-ltem Short-Form Health Status (SF-36) Ware et al. (1993) and the Gastrointestinal Symptom Rating Scale (Svedlund J, Dimenäs E, Wiklund I, 1995).

The SF-36 questionnaire consists of 36 questions grouped into eight domains: physical functioning (PF), social functioning (SF), role limitation related to physical problems (RP), role limitation, gender associated with emotional problems (RE), mental health (MH), vitality (VT), body pain (VP) and perception of general health $(\mathrm{GH})$. The indicators of each scale are compiled as follows: the higher the value of the indicator (from 0 to 100), the better the score on the selected scale. They form two parameters that evaluate the eight concepts of health: psychological and physical components. The physical components are: $\mathrm{GH}$ - general perception of health, PF - limitations in physical activity due to health problems, RP - limitations in normal role-playing activities due to physical health problems, BP - physical pain. Mental components include: SF - limitations in social activity due to physical or emotional problems, $\mathrm{MH}$ - general mental health (psychological distress and well-being, RE - limitations in normal role activity due to emotional problems, VT - viability (energy and fatigue) The scores of each scale vary between 0 and 100, where 100 is a completely healthy, and the results are in the form of scores compiled in such a way that a higher score indicates a higher $Q O L$ level. The general questionnaire is a general questionnaire that can be used for patients with various pathologies as well as for population-based studies. of 15 questions grouped into five clusters for a detailed study of symptoms reflecting reflux, abdominal pain, indigestion, diarrhea, and constipation. GSRS has a seven-point Likert-type scale, where "1" means no problem symptoms and "7" means no very problematic symptoms. The reliability and validity of this questionnaire are well documented, the values of the norms for the general population are available (Kulich et.al., 2008).

\section{Results and Discussion}

The dynamics of the physical components of quality of life under the influence of the proposed comprehensive treatment in our examined patients is presented in Figure 1.

Under the influence of the basic therapy among the patients of the Comparison Group the General Health (GH) improved by $33.03 \%$, changing from $52.81 \pm 0.98$ to $78.86 \pm 1.03(\mathrm{p}$ $<0.05$ ). While in the groups on the background of complex treatment it increased by $42.52 \%$ (from $54.3 \pm 0.97$ to $94.5 \pm 1.97$ ) in patients of the first group, by $13.10 \%$ (from $62.01 \pm 1.87$ to $71.36 \pm$ 0.61 ) - in II and $46.28 \%$ (from $50.81 \pm 1.07$ to 94.6 \pm 2.01 ) - in the III, respectively (p1 , p2, p3 <0.05). 

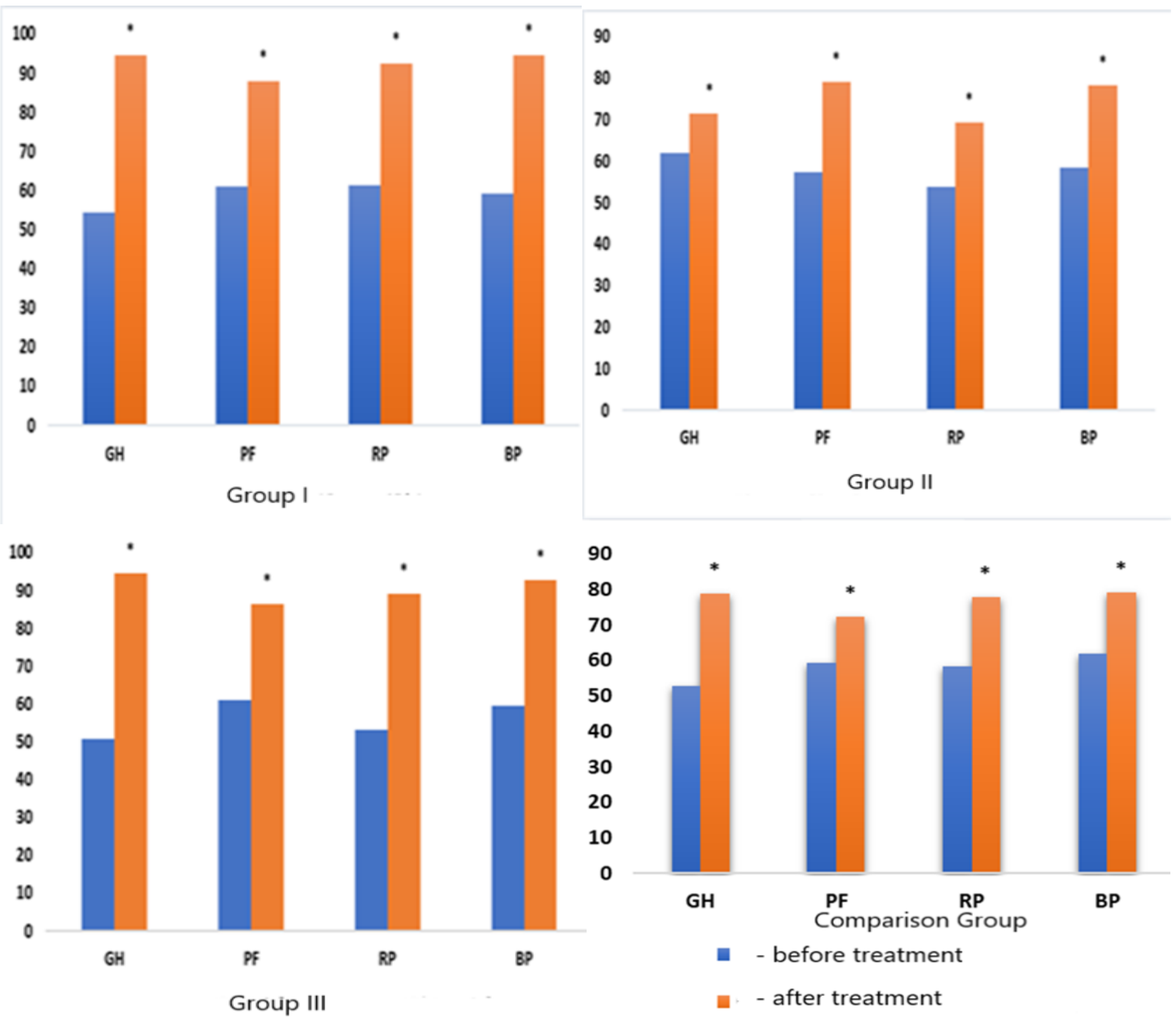

Fig. 1. Dynamics of quality of life indicators (physical component) in the examined patients

Note: * $(p<0,05)$ data are reliable for indicators before and after treatment.

Physical Functiong Scale (PF) improved by $17.9 \%$ under the influence of the prescribed treatment (from $59.32 \pm 0.97$ to $72.3 \pm 0,61$ ) in patients of the Comparison Group ( $p<0.05)$ and by $30.38 \%$ (from $61.12 \pm 1.38$ to $87.8 \pm 2.09$ ) - in the I Group; $27.47 \%$ (from $57.01 \pm 2.63$ to 79.03 \pm 0.97 ) - in the II Group; $29.17 \%$ (from $61.12 \pm$ 0.68 to $86.3 \pm 1.16$ ) - in the III Group, respectively (p1, p2, p3<0.05).

Role Physical Scale (RP) scores improved by $25.14 \%$ (from $58.31 \pm 0.91$ to $77.9 \pm 1.12$ ) in Comparison Group ( $\mathrm{p}<0.05$ ) and by $33.6 \%$ (from $61.24 \pm 1.12$ to $92.3 \pm 2.07)$ in patients of the I Group, by $22.58 \%$ (from $53.71 \pm 0.76$ to $69.38 \pm$
1.56) - in the II Group, by $40.20 \%$ (from $53.20 \pm$ 0.13 to $89.12 \pm 0.97)$ - in the III (p1, p2, p3<0.05) Dynamics of data in Body Pain (BP) scale under the influence of the proposed therapy improved by $21.84 \%$ (from $61.9 \pm 0.89$ to $79.2 \pm 1.33$ ) in patients of the Comparison Group $(p<0.05)$ and by $37.28 \%$ (from $59.2 \pm 0.86$ to $94.4 \pm 1.25$ ) - in the I Group, by $25.46 \%$ (from $58.36 \pm 1.15$ to 78.3 \pm 2.13 ) - in the II Group, by $35.92 \%$ (from 59,41 \pm 1.08 to $92.73 \pm 1.05)$ - in the III Group (p1, p2, p3 <0.05).

Dynamics of mental components of quality of life under the influence of the offered complex treatment at the patients examined by us is presented in figure 2. 

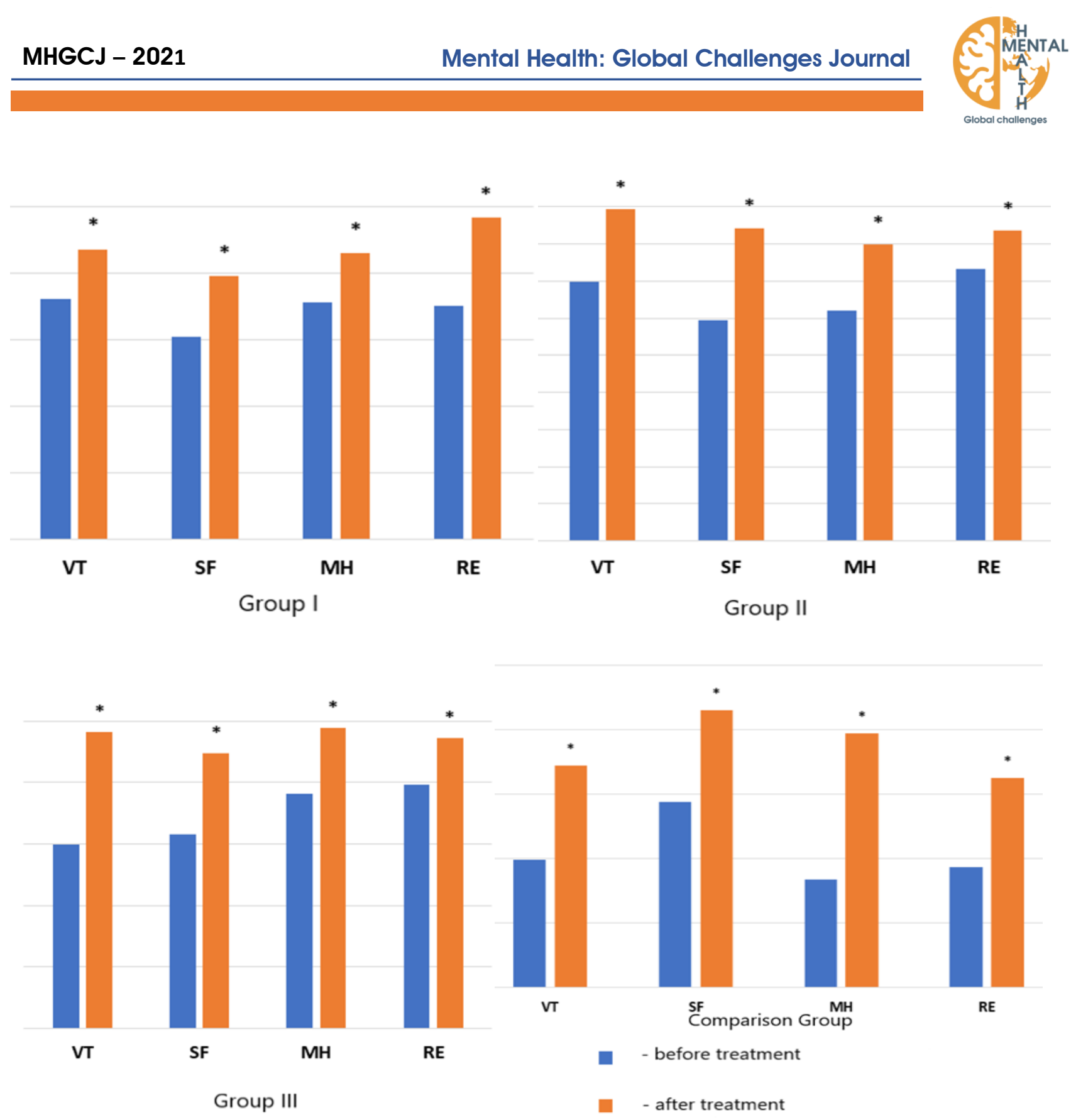

Fig. 2. Dynamics of quality of life indicators (mental component) in the examined patients

Notes: $1 . *$ - $(p<0,05)$ data are reliable in relation to indicators before and after treatmen

Under the influence of complex therapy, the values of the Vitality (VT) increased by $17.18 \%$ (from $72.3 \pm 1.62$ to $87.3 \pm 0.97$ ) in patients of Group I, by $21.93 \%$ (from $69.76 \pm 1.32$ to $89.36 \pm$ 1.36) - in the Group II, in which the basic therapy was added to the calcium drug; by $37.87 \%$ (from $59.86 \pm 0.96$ to $96.36 \pm 2.31$ ) - in the Group III, to which both drugs were added to the basic therapy (p1, p2, p3 <0.05). Among patients with GERD without UCTD, who received basic therapy with PPIs and alginate-antacid formulation, the influx of strength and energy felt $9.50 \%(69.86 \pm 0.32$ to $77.2 \pm 1.08), p<0.05$.

Data of Social Functioning Scale (SF) under the influence of the proposed therapy improved by $8.8 \%$ (from $74.36 \pm 0.98$ to $81.5 \pm 1.64$ ) in patients of the Comparison Group $(p<0,05)$ and by $22.7 \%$ (from $61.12 \pm 0.81$ to $79.1 \pm 0.62$ ) in patients in the Group I, by $29.6 \%$ (from $59.36 \pm$ 1.65 to $84.3 \pm 1.31$ ) - in the Group II, by $29.31 \%$ (from $63.16 \pm 0.38$ to $89.36 \pm 1.13$ ) - in the Group III (p1, p2, p3<0.05).

Mental Health Scale (MH) improved by $17.23 \%$ (from $71.26 \pm 0.36$ to $86.1 \pm 1.95$ ) in patients of the Group I, by $22.41 \%$ (from $61.96 \pm 0.68$ to 
$79.86 \pm 1.07$ ) - in the Group II, $21.96 \%$ (from 79.19 \pm 1.02 to $97.63 \pm 2.03)$ - in the Group III (p1, p2, p3 <0.05) and 14.22\% (from $68.36 \pm 0.35$ to 79.7 $\pm 1.04)$ - in the Comparison Group $(p<0.05)$.

Also in the patients we treated there was a positive dynamics of the scale Role Emotional functioning (RE): by $27.37 \%$ (from $70.3 \pm 1.16$ to $96.8 \pm 2.07$ ) in patients of the Group I, by $12.36 \%$ (from $73.26 \pm 0.64$ to $83.6 \pm 1.35$ ) - in the Group II, by $15.7 \%$ (from $79.43 \pm 0.38$ to $94.3 \pm 0.92$ ) in the Group III (p1, p2, p3 <0.05) and 9.05\% (from $69.3 \pm 0.31$ to $76.2 \pm 0.82)$ - in patients of the Comparison Group who received basic therapy ( $\mathrm{p}$ $<0.05)$.

\section{Conclusions}

Thus, the inclusion in the standard therapy of gastroesophageal reflux disease in patients with its development on the background of undifferentiated connective tissue dysplasia of magnesium lactate dihydrate in combination with pyridoxine hydrochloride ("Magne -B6 ") and calcium carbonate in combination with cholecalciferol ("Calcium-D3 Nicomed") contributed to a significant improvement in their quality of life.

\section{Conflict of interest}

The authors declare that they have no conflict of interest.

\section{References}

Alshammari, S. A., Alabdulkareem, A. M., Aloqeely, K. M., Alhumud, M. I., Alghufaily, S. A., AlDossare, Y. I., \& Alrashdan, N. O.. (2020). The Determinants of the Quality of Life of Gastroesophageal Reflux Disease Patients Attending King Saud University Medical City. Cureus. https://doi.org/10.7759/cureus.9505

Gorczyca, R., Pardak, P., Pękala, A., \& Filip, R.. (2019). Impact of gastroesophageal reflux disease on the quality of life of Polish patients. World Journal of Clinical Cases, 7(12), 14211429.

https://doi.org/10.12998/wjcc.v7.i12.1421

Hill, C., Versluiis, Y., Furay, E., Reese-White, D., Holan, C., Alexander, J., Doggett, S., Ring, D., \& Buckley, F. P.. (2020). Psychoemotional factors and their influence on the quality of life in patients with GERD. Surgical Endoscopy. https://doi.org/10.1007/s00464-020-08145-8

Iudici, M., Irace, R., Riccardi, A., Cuomo, G., Vettori, S., \& Valentini, G.. (2017). Longitudinal analysis of quality of life in patients with undifferentiated connective tissue diseases. Patient Related Outcome Measures, Volume 8, 7-13. https://doi.org/10.2147/prom.s1 17767

Kulich, K. R., Madisch, A., Pacini, F., Piqué, J. M., Regula, J., Van Rensburg, C. J., Újszászy, L., Carlsson, J., Halling, K., \& Wiklund, I. K.. (2008). Reliability and validity of the Gastrointestinal Symptom Rating Scale (GSRS) and Quality of Life in Reflux and Dyspepsia (QOLRAD) questionnaire in dyspepsia: A six-country study. Health and Quality of Life Outcomes, 6(1), 12. https://doi.org/1 0.1 186/1477-7525-6-12

Romash, I., Mishchuk, V. (2019). Improvement of Magnesium and Calcium Deficiency in Patients with Gastroesophageal Reflux Disease Associated with Undifferentiated Connective Tissue Disease. Galician Medical Journal, 26(4). https://doi.org/10.21802/gmj.2019.4.3

Romash, I. (2020). Disorders of social functioning and quality of life in patients with gastroesophageal reflux disease while combined with undifferentiated connective tissue dysplasia. Mental Health: Global Challenges Journal, 3(1), 11-16. https://doi.org/10.32437/mhgcj.v3i1.100

Romash, I.R., Vynnyk, M.I. (2020). Dynamics of Quality of Life Indices in Case of Metabolic Syndrome in Patients with Paranoid Schizophrenia on the Background of Atypical Neuroleptic Agents Application and Improvement of Comorbidity. Ukrains'kyi visnyk psykhonevrolohii. 27, 4 (101):62-67. doi: https://doi.org/10.36927/2079-0325-V27-is42019-11

Salome Satya Vani P et al., (2018). Assessment on Patients Health Related Quality of Life Associated With Gerd. Int J Recent Sci Res. 9(4), pp. 25840-25845. DOl: http://dx.doi.org/10.24327/ijsr.2018.0904.1940 )

Yamasaki, T., Quan, S. F., \& Fass, R. (2019). The effect of sleep deficiency on esophageal acid exposure of healthy controls and patients with gastroesophageal reflux disease. Neurogastroenterology and motility: the official journal of the European Gastrointestinal Motility Society, 31(12), el3705. https://doi.org/10.111 1/nmo. 13705 